Board of Governors of the Federal Reserve System

International Finance Discussion Papers

Number 446

June 1993

MARKET SHARE AND EXCHANGE RATE PASS-THROUGH IN WORLD AUTOMOBILE TRADE

Robert C. Feenstra, Joseph E. Gagnon, and Michael M. Knetter

NOTE: International Finance Discussion Papers are preliminary materials circulated to stimulate discussion and critical comment. References to International Finance Discussion Papers (other than an acknowledgment that the writer has had access to unpublished material) should be cleared with the authors. 


\begin{abstract}
$\underline{\text { ABSTRACT }}$
This paper explores the relationship between exchange rate pass-through and market share for monopolistically competitive exporters. Under fairly general assumptions we show that pass-through should be high for exporters based in a country with a very large share of total destination market sales. For source countries with small and intermediate market shares, the theoretical relationship is potentially nonlinear and sensitive to assumptions about the nature of consumer demand and firm interactions. The model is estimated using a panel data set of automobile exports from France, Germany, Sweden, and the United States to a variety of destinations over the period 1970-88. The empirical relationship between pass-through and market share is significantly nonlinear: pass-through is lowest when the source country's market share is around 45 percent and it is highest when the source country's share approaches 100 percent.
\end{abstract}




\section{Market Share and Exchange Rate Pass-Through in World Automobile Trade}

\section{Robert C. Feenstra, Joseph E. Gagnon, and Michael M. Knetter ${ }^{1}$}

Theoretical and empirical research in international trade has focused increasingly on environments in which firms have the ability to set prices. New trade theory has applied models of imperfect competition from industrial organization to trade in international markets. There has been a corresponding increase in empirical studies of price behavior in international markets; in particular, in studies of the related issues of exchange rate "pass-through"--which refers to the response of import prices to exchange rates--and "pricing to market"--which refers to price discrimination across export markets that is correlated with exchange rate movements. The ample evidence that import prices do not respond proportionately to exchange rates (i.e., incomplete pass-through) is widely attributed to market power. The convincing evidence of price discrimination across buyers from different countries that varies with exchange rates (i.e., pricing to market) demonstrates that markets for manufactured goods are not well-integrated. These results support the shift in emphasis to imperfect competition in trade.

Empirical studies of pass-through and pricing to market consist mainly of descriptive statistical models, as opposed to the estimation of structural models of

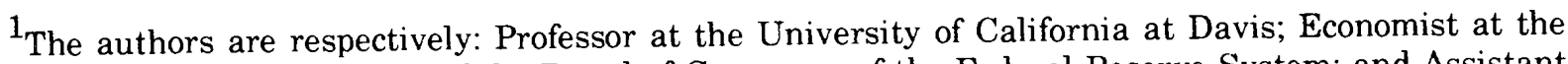
International Finance Division of the Board of Governors of the Federal Reserve System; and Assistant Professor at Dartmouth College. This research was performed in part while Gagnon visited the University of California at Berkeley. We thank Neil Ericsson, Jon Faust, Bill Helkie, Andrew Levin, Cathy Mann, Jaime Marquez, and Jim Tybout for comments, and Ari Kletzky and Mark Unferth for research assistance. We also thank seminar participants at the Federal Reserve Board and the 1993 Winter Meetings of the American Economic Association. This paper represents the views of the authors and should not be interpreted as reflecting the views of the Board of Governors of the Federal Reserve System or other members of its staff.
} 
market behavior, largely because of limitations in the availability of consistent data on prices, quantities, costs, trade restrictions, and other factors relevant to pricing in international markets. Nonetheless, these studies are quite informative about the response of traded goods prices to exchange rate changes, given the large magnitude of changes in exchange rates between industrialized countries, relative to other cost shocks, in the last two decades.

A common pattern in many of these studies has been the tendency to observe less pass-through or, alternatively, more pricing to market, on shipments from foreign countries to the United States than on shipments to other foreign markets from the United States. This regularity appears in the work of Mann (1986), Knetter (1989), Marston (1990), Ohno (1989), Gagnon and Knetter (1990) and others. More recent work by Knetter (1993) finds that variations in pricing-to-market behavior across industries are even more important than variations across source and destination countries. For the automobile industry, Mertens and Ginsburgh (1985), Kirman and Schueller (1992), and Le Cacheux and Reichlin (1992) document a significant degree of price discrimination and pricing to market within the European Community.

Market structure and trade restrictions, which are likely to vary a great deal by industry and by source and destination, may help explain the wide industry-specific variation in pass-through and pricing to market. This paper examines one way in which market structure may affect pass-through and pricing to market. We begin by deriving a general theoretical relationship between passthrough and market share, defined to be the export country's share of total sales in 
a particular destination market. The main result is that pass-through tends to be highest for very high market shares. When market share is very high, the firms face little competition that has not experienced a similar change in costs, and thus will more fully pass through an exchange rate change for a given market demand schedule. Pass-through may rise steadily from low market shares to high market shares or it may decrease with market share for low market shares before rising as market share becomes larger.

We then consider whether price adjustment on automobile shipments by the United States, Germany, France and Sweden to 12 destination markets is consistent with the predictions of the model. This section of the paper extends the data set and empirical approach taken by Gagnon and Knetter (1990). We allow pass-through to vary systematically by source and destination market, and according to the market share. The empirical results confirm the main prediction of the model: Pass-through rises with market share at an increasing rate as share becomes large. The relationship between pass-through also appears to be significantly nonlinear, as passthrough decreases with market share for small market shares. Finally, we find evidence that source and destination market effects are important for pass-through in automabile trade. 


\section{Theoretical Model}

The model of this paper is an extension of Feenstra (1989) and Knetter (1989). ${ }^{2}$ We shall consider the market for a differentiated product, such as automobiles. The demand for variety $i$ is denoted by $x_{i}(\underline{P}, I) i=1, \ldots, N$, where $\underline{P}=\left(p_{1}, \ldots, p_{n}\right)$ is the price vector in units of the buyers' currency (say, dollars) and $I$ is total expenditure on all varieties. ${ }^{3}$ Some of the varieties can be produced domestically, while others are imported. We assume that each firm produces a single variety, and treats the prices of the other firms as fixed, i.e., they are Bertrand competitors. In addition, we shall assume that firms treat total expenditure $I$ as fixed when determining their optimal price. Letting $c_{i}^{*}$ denote the marginal cost of an exporter in its own currency (say, yen), and $e_{i}$ the exchange rate (dollars/yen), the profit maximization problem for an exporter to the United States is:

$$
\underset{p_{i}}{\max }\left(p_{i}-e_{i} c_{i}^{*}\right) x_{i}(\underline{P}, I),
$$

where $p_{i}$ is the price quoted in dollars. ${ }^{4}$ For domestic producers, the profit maximization problem is very similar, except that the marginal $\operatorname{cost} e_{i} c_{i}^{*}$ is replaced

\footnotetext{
${ }^{2}$ Fisher (1989) and Harrison (1992) develop theories of exchange rate pass-through aınd market structure for the case of a homogeneous good. See Marquez (1991) for a treatment of pass-through in the context of the Rotterdam model of consumption applied to total U.S. imports disaggregated by source.

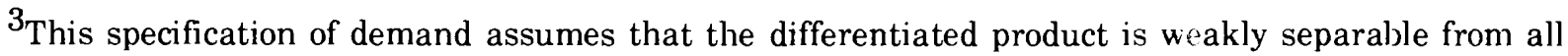
other goods in the consumer's utility function.

${ }^{4}$ Since we are treating the exchange rate and other variables as non-stochastic, there is no difference between setting the price in the currency of the exporter or the importer. The model assumes that marginal cost is constant with respect to the volume of sales and the exchange rate. The empirical section relaxes these assumptions.
} 
by $c_{i}$.

The first-order condition for (1) is familiar:

$$
p_{i}=e_{i} c_{i}^{*}\left[\eta_{i} /\left(\eta_{i}-1\right)\right]
$$

where $\eta_{i}=-\left(\partial x_{i} / \partial p_{i}\right)\left(p_{i} / x_{i}\right)$ is the (positive) elasticity of demand, which depends on the price vector $\underline{P}$ and expenditure $I$. Since the demand function $x_{i}(\underline{P}, I)$, is homogeneous of degree zero in $(\underline{P}, I)$, then the derivative $\partial x_{i} / \partial p_{i}$ is homogeneous of degree negative one in these arguments. It follows that the elasticity $\eta_{i}$ is homogeneous of degree zero in $(\underline{P}, I)$, and this condition will be used below.

To determine the effect of a change in the exchange rate on the import price, differentiate (2) to obtain:

$$
\frac{\partial \ln p_{i}}{\partial \ln e_{i}}=\left[1+\frac{1}{\left(\eta_{i}-1\right)} \frac{\partial \ln \eta_{i}}{\partial \ln p_{i}}\right]^{-1} .
$$

We shall refer to this expression as the pass-through elasticity, which must be positive from the second-order conditions for profit maximization. Its magnitude clearly depends on how the elasticity of demand changes along the demand curve: if the elasticity increases (decreases) as the price rises, then pass-through is less (greater) than unity. This expression can be simplified by differentiating the log elasticity $\ln \left(\eta_{i}\right)=\ln \left(-\partial x_{i} / \partial p_{i}\right)+\ln p_{i}-\ln x_{i}$ with respect to price, to obtain: 


$$
\frac{\partial \ln p_{i}}{\partial \ln e_{i}}=\left[2+\frac{1}{\left(\eta_{i}-1\right)}\left(\frac{\partial \ln \left(-\partial x_{i} / \partial p_{i}\right)}{\partial \ln p_{i}}+2\right)\right]^{-1}
$$

In this form, the pass-through elasticity is seen to depend on a measure of the curvature of the demand curve relative to the demand elasticity itself. Further simplification will be possible when the market share of variety $i$ is very small, as considered next.

\section{Small Market Share}

We shall suppose that each product variety has a finite reservation price, at which demand equals zero. This price will depend in general on the prices of all other varieties and total expenditure. Thus, letting $\underline{P}^{-i}$ denote the price vector $\underline{P}$ with the $i^{\text {th }}$ component deleted, the reservation price for variety $i$ is denoted by $\phi_{i}\left(\underline{P}^{-i}, I\right)$. We shall assume that the demand function is well-behaved in a neighborhood of the reservation price, in the following sense:

Assumption 1: There are bounds $\mathrm{B}_{1}, \mathrm{~B}_{2}$ and $\varepsilon>0$ such that as $p_{i} \rightarrow \phi_{i}\left(\underline{P}^{-i}, I\right)$ then

$$
\epsilon<\lim \left|\frac{\partial x_{i}}{\partial p_{i}}\right|<B_{1} \text { and } \lim \left|\frac{\partial^{2} x_{i}}{\partial p_{i}^{2}}\right|<B_{2}
$$

This is a relatively weak assumption on demand, but it rules out the demand equation from a CES utility function, for which the reservation prices are infinity; 
that case will be discussed at the end of this section. When Assumption 1 is satisfied, then it is immediate that $\eta_{i} \rightarrow \infty$ as $p_{i} \rightarrow \phi_{i}\left(\underline{P}^{-i}, I\right)$, since demand $x_{i}$ approaches zero. Moreover, the curvature of the demand curve $\partial \ln \left(-\partial x_{i} / \partial p_{i}\right) / \partial \ln p_{i}$ will have a finite limiting value as $p_{i}$ approaches its reservation value. Then from (3') we immediately obtain:

Proposition 1: Under Assumption 1, as $p_{i} \rightarrow \phi_{i}\left(\underline{P}^{-i}, I\right)$ then $\partial \ln p_{i} / \partial \ln e_{i} \rightarrow 1 / 2$.

Thus, for any product varieties with very small market shares, whose prices must be close to their reservation levels, the pass-through elasticity will be approximately onehalf. This is a remarkably strong result for the broad range of demand functions allowed by Assumption 1. The explanation is that, in a neighborhood of the reservation price, the response of the firm to changes in marginal cost is identical to that obtaineci by linearizing the demand curve. With the slope of the linearized and actual demand curves equal at the reservation price, then the corresponding marginal revenue curves are arbitrarily close for $p_{i}$ close to $\phi_{i}\left(\underline{P}^{-i}, I\right)$. It is well known that pass-through for the linear case equals one-half (since marginal revenue is twice the slope of demand), and we obtain this same value as a limiting case for all demand functions satisfying Assumption $1 .^{5}$

As the price falls below its reservation level, and market share increases, what

\footnotetext{
5 For a linear demand curve, pass-through equals one-half when evaluated as a derivative, $\partial p_{i} / \partial\left(e_{i} c_{i}^{*}\right)$ $=1 / 2$. Then in elasticity form we obtain $\left(\partial p_{i} / \partial e_{i}\right)\left(e_{i} / p_{i}\right)=e_{i} c_{i}^{*} / 2 p_{i}$, which is less than one-half except when price equals marginal cost, at zero demand.
} 
happens to the pass-through elasticity? For any finite value of $\eta_{i}>1$, we see that:

$$
\frac{\partial \ln p_{i}}{\partial \ln e_{i}} \geq \frac{1}{2} \longrightarrow \frac{\partial \ln \left(-\partial x_{i} / \partial p_{i}\right)}{\partial \ln p_{i}} \leq-2 \longrightarrow \frac{\partial^{2} x_{i}}{\partial p_{i}^{2}} \frac{\geq}{<} \frac{2}{p_{i}}\left|\frac{\partial x_{i}}{\partial p_{i}}\right| .
$$

The second-order condition for maximizing profits in (1) can be expressed as,

$$
\frac{\partial^{2} x_{i}}{\partial p_{i}^{2}}<\frac{2}{p_{i}}\left|\frac{\partial x_{i}}{\partial p_{i}}\right| \eta_{i}
$$

Comparing (4) and (5), we see that either of the cases in (4) are consistent with the second-order conditions, and can certainly occur. ${ }^{6}$ Thus, as the market share rises above zero, pass-through can be greater or less than one-half. As the market share becomes large, approaching unity, additional restrictions on demand will allow us to determine the pass-through elasticity more precisely, as discussed in the next, section.

\section{$\underline{\text { Large Market Share }}$}

When considering large market shares, we wish to avoid a single firm having significant market power. Rather, we will consider the expenditure share obtained in a destination market by a group of exporting firms $i=1, \ldots, M$, all from the same source country. As $M$ grows, the exporting country share in that destination market will also rise. In particular, as $M$ approaches $N$ (the total number of product

\footnotetext{
${ }^{6}$ An example of the pass-through elasticity falling below one-half is provided by linear demand, considered in the previous footnote.
} 
varieties), the exporting country share in that destination market will approach unity. We are interested in solving for the pass-through elasticity in this limiting case.

The first-order condition for each exporting firm is still stated as (2), where the exchange rate $e_{i}$ takes the common value of $e$ for $i=1, \ldots, M$. We shall suppose that the prices and elasticities also take the common values $p_{i}=p$ and $\eta_{i}=\eta$ for $i=1, \ldots$, $M$, so that the equilibrium is symmetric across the exporting firms. Then the effect of changes in the exchange rate on the common import price is: 7

$$
\frac{\partial \ln p}{\partial \ln e}=\left[1+\frac{1}{\eta-1} \sum_{i=1}^{M} \frac{\partial \ln \eta}{\partial \ln p_{i}}\right]^{-1}
$$

In comparison with (3), we see that this pass-through elasticity depends on how the demand elasticity $\eta$ adjusts when all the prices $p_{i}, i=1, \ldots, M$ change. To determine this effect, recall that the demand elasticity $\eta$ is homogeneous of degree zero in $(\underline{P}, I)$, and it follows that the elasticities of $\eta$ with respect to these variables sum to zero. Some simplification is provided by the following restriction on demand:

Assumption 2: $x_{i}(\underline{P}, I)=f_{i}(\underline{P}) I, i=1, \ldots, N$, so that income elasticities of demand are unity.

\footnotetext{
${ }^{7}$ It should be emphasized that (6) holds constant the prices of other varieties $j=M+1, \ldots, N$. In general, these prices would change as $p$ does, which would further affect the value of $p$. However, in our estimating equation, we will include the prices of other varieties as explanatory variables, so we are interested here in the partial effect of $e$ on $p$.
} 
Under this assumption, the price elasticities of demand are $\eta_{i}=-\left(\partial f_{i} / \partial p_{i}\right)\left(p_{i} / f_{i}\right)$, which do not depend on expenditure $I$. Thus, the elasticities of $\eta_{i}$ with respect to changes in all prices must sum to zero. If we presume that $\eta_{i}$ is increasing in its own price $p_{i}$ then it must be decreasing in at least some of the other prices $p_{j}$.

Referring back to (6), $\eta$ denotes any one of the elasticities $\eta_{i}, i=1, \ldots, M$. In the symmetric equilibrium, we can suppose that $\eta_{i}$ has the same elasticity with respect to any of the other prices $p_{j}$ from that exporting country, $j=1, \ldots, M, j \neq i$. If the elasticity of $\eta_{i}$ with respect to $p_{i}$ is positive in (6), tending to make the passthrough less than unity, then all other terms in the summation are negative, tending to raise the pass-through. The reason for this is that with multiple firms exporting from a source country, their optimal prices will respond to both the exchange rate and the prices of other firms: as all import prices rise with an appreciation of the source country currency, the increase in its competitors' prices will make each firm more willing to increase its own. This feedback effect is most pronounced when the source country is the only supplier in the destination market, so that it has market share of unity. In that case $M=N$, and under Assumption 2, the summation appearing in (6) equals zero. We then have:

Proposition 2: Under Assumption 2, when $M=N$ so the exporting country has a share of unity in the destination market, then $\partial \ln p / \partial \ln e=1$.

While we have already provided some intuition for this result, a further 
exploration may be helpful. Under Assumption 2, the elasticity $\eta_{i}$ in the first-order condition (2) does not depend on expenditure $I$, and is homogeneous of degree zero in $\underline{P}$. Then if all varieties are supplied from the same exporting country, and there is an equi-proportional change in prices due to movements in the exchange rate, the elasticity $\eta_{i}$ will not change. Then it is immediate from (2) that movements in the exchange rate must be fully reflected in the import price, so that the pass-through elasticity is unity.

Our results can be summarized in Figure 1, where we graph the passthrough elasticity depending on the share of an exporting country in a destination market. For very low market shares, the price of the exporting firm(s) must be close to their

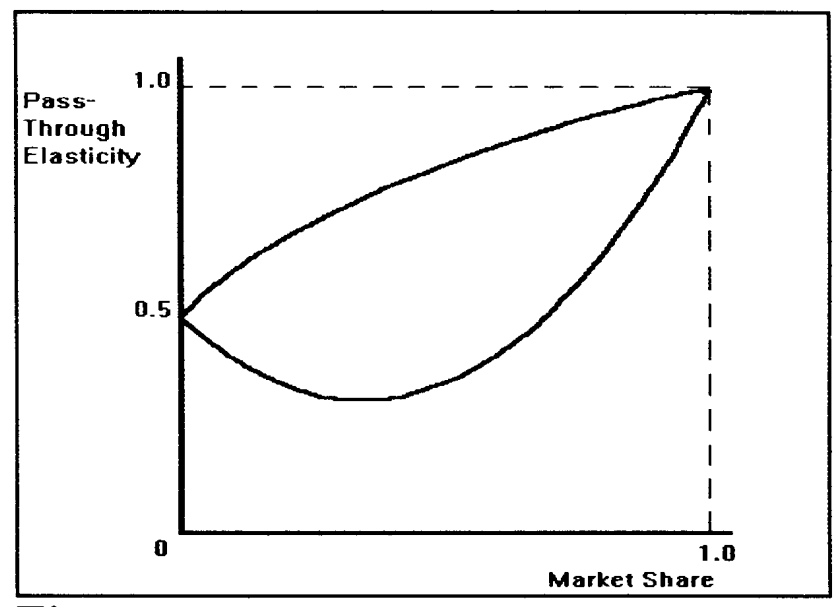

Figure 1

reservation level, and the pass-through elasticity is approximately one-half under Assumption 1. For higher market shares, pass-through can either fall below or rise above this range, as illustrated. Under Assumption 2, as the market share approaches unity so does the pass-through. The general relationship that is suggested is a pass-through elasticity that might initially decline as market share rises, but will increase towards unity as market share approaches 100 percent. 


\section{CES Utility}

The previous two subsections discussed the relationship between market share and pass-through under very general assumptions about the nature of consumer demand. This subsection shows that even more specific results can be obtained if one is willing to make a more restrictive assumption about consumer demand, namely that consumers have a constant elasticity of substitution across automobiles produced by different firms. (Recall that the case of CES utility was ruled out in the first subsection.)

In general, when the elasticity of substitution--denoted by $\sigma$--is constant, the elasticity of demand perceived by firm $i$ is given by $\eta_{i}=\sigma\left(1-s_{i}\right)+s_{i}$, where $s_{i}$ is the firm's market share. For the $i=1, \ldots, M$ exporting firms in a given country, we assume that the destination market shares and prices take the common values $s_{i}=$ $s$ and $p_{i}=p$. Substituting the firm's perceived demand elasticity into equation (3) yields an expression for the pass-through elasticity in the CES case:

$$
\frac{\partial \ln p_{i}}{\partial \ln e_{i}}=1-\left[\frac{s-M s^{2}}{\left(\frac{\sigma}{\sigma-1}\right)(1-s)-(M-1) s^{2}}\right] .
$$

The expression in brackets on the right of (7) is the ratio of two quadratic functions of the market share, $s$. The numerator equals zero when $s=0$ or $s=1 / M$, where in the latter case the $M$ exporting firms have obtained the entire market in the destination country $(M s=1)$. For intermediate values of the market share, $0<s<$ $1 / M$, the numerator is positive, and is maximized when the total share in the 
destination market is $M s=1 / 2$. The quadratic function in the denominator is declining in $\mathrm{s}$ (and positive for $0<=s<=1 / M$ ). This means that the pass-through elasticity will be minimized at a total market share of $M s>1 / 2$, and the pass-through elasticity equals unity for $s=0$ and $s=1 / M$.

Let $S=M s$ denote the total share of the exporting firms from a given country in the destination market. Then lower and upper bounds for the expression in (7) are:

$$
1-\left(\frac{\sigma-1}{\sigma M}\right)\left(\frac{M}{M-1}\right)^{2}\left(S-S^{2}\right) \leq \frac{\partial \ln p}{\partial \ln e} \leq 1-\left(\frac{\sigma-1}{\sigma M}\right)\left(S-S^{2}\right)
$$

If $M$ is reasonably high, then we could conclude that the pass-through elasticity is well-approximated by a quadratic function of the exporting country's share in the destination market. This will be the functional form we adopt in estimation. Figure 2 graphs the pass-through elasticity as a function of $S$ for fixed values of $M$ and $\sigma$. Note that equation (7) implies that pass-through is unity for $S=0$ and $S=1$. These endpoint conditions will not be imposed in estimation, and from our discussion in the last section, we do not expect the

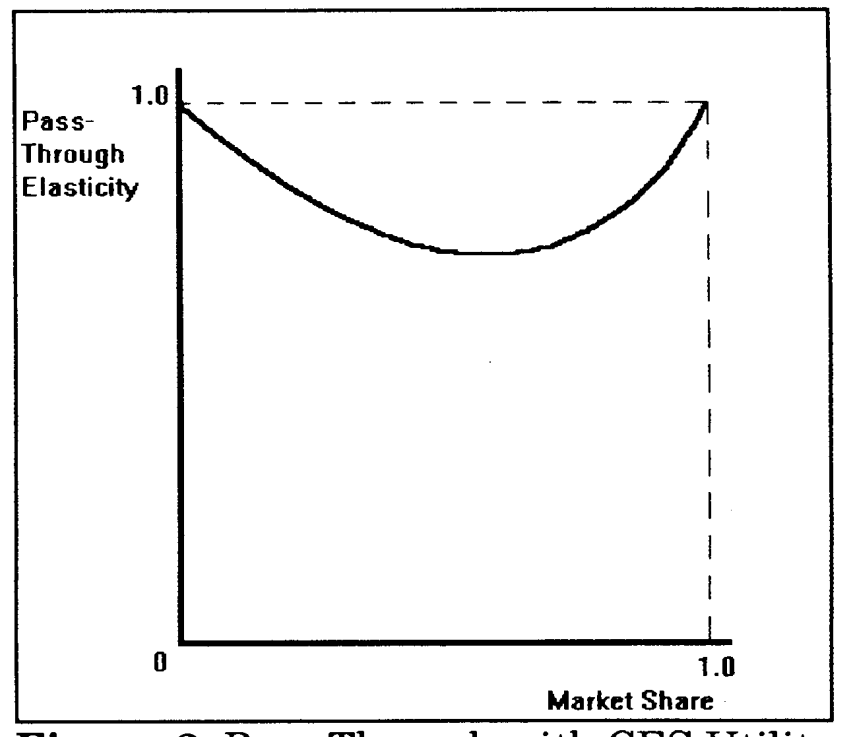

Figure 2 Pass-Through with CES Utility former condition to hold outside the CES case. 


\section{Discussion}

The CES model described above offers relatively specific predictions: Passthrough may approximate a quadratic function that equals one for market shares of zero and unity and lies below one between these extreme values of market share. The model with more general demand curves and a finite reservation price predicts pass-through equal to one-half as market share approaches zero and pass-through equal to one as market share approaches unity. Other models of imperfect competition also suggest that pass-through should increase as the market share of the foreign firms rises. 8 We shall investigate the empirical relationship between pass-through and market share for the automobile industry next.

\section{Empirical Implementation}

From the first-order condition (2), the optimal price $p_{i}$ depends on the marginal costs, all other prices, and total expenditure. We can write this price as a function,

$$
p_{i}=\pi_{i}\left(e_{i} c_{i}^{*}, \underline{P}^{-i}, I\right)
$$

Since the demand elasticity $\eta_{i}$ is homogeneous of degree zero in $(\underline{P}, I)$, the function $\pi_{i}$ is homogeneous of degree one in all its arguments. We shall be measuring prices in terms of the exporter's currency, denoted $p_{i}^{*}=p_{i} / e_{i}$. Then dividing (8) through by $e_{i}$, we obtain the pricing equation,

\footnotetext{
${ }^{8}$ See, for example, the Cournot model in Dornbusch (1987) and the Rotterdam model in Marcuez (1991).
} 


$$
p_{i}^{*}=\pi_{i}\left(c_{i}^{*}, \frac{\underline{P}^{-i}}{e_{i}}, \frac{I}{e_{i}}\right)
$$

We shall distinguish the export price from country $i$ by the destination market $j$ and year $t$. Adding these subscripts to the variables in ( $\left.8^{\prime}\right)$, we consider the following functional form:

$$
\ln p_{i j t}^{*}=\mu_{i j}+\beta_{i j t} \ln c_{i t}^{*}+\left(1-\beta_{i j t}\right) \ln \left(p_{j t}^{-i} / e_{i j t}\right)+\gamma_{i j} \ln \left(I_{j t} / e_{i j t}\right)
$$

In this expression, $\mu_{i j}$ is an intercept term that differs across source and destination markets in order to capture differences in markups or quality that are constant over time. The elasticity of the export price with respect to marginal cost is precisely the pass-through elasticity in (3) and (6), and is denoted by $\beta_{i j t}$. The term $p_{j t}^{-i}$ is the aggregate price of all varieties in destination $j$ except those from source $i$, measured in units of the importer's currency. Dividing by $e_{i j t}$ converts this to the exporter's currency. 'The term $I_{j t} / e_{i j t}$ denotes total expenditure on automobiles in destination $j$ converted into exporter $i$ 's currency. $\gamma_{i j}$ is the elasticity of price with respect to total expenditure. ${ }^{9}$ Finally, we will allow the pass-through elasticity to depend on market share as well as source and destination effects, with:

$$
\beta_{i j t}=\beta_{0 i j}+\beta_{1} s_{i j t}+\beta_{2} s_{i j t}^{2},
$$

\footnotetext{
${ }^{9}$ Recall that under Assumption 2, $\gamma$ equals zero.
} 
where $s_{i j t}$ is the share of source $i$ exporters in destination market $j$ for year $t$. Substituting (10) into (9), we obtain an equation that is nonlinear in the parameters, and will be estimated.

In the estimating equation, the response of export prices to domestic costs and competitors' prices (all measured in the exporter's currency) is constrained to be homogeneous of degree one: a 10 percent increase in costs matched by a 10 percent increase in competitors' prices leads to a 10 percent increase in export prices. From the buyer's point of view, this constraint imposes symmetry between pass-through of producer cost shocks and exchange rate changes. In practice, the data did not reject this homogeneity restriction.

$\underline{\text { Data }}$

The data used in this study are annual observations from 1970 through 1988 compiled using national sources in seven automobile-producing countries: Canada, France, Germany, Japan, Sweden, the United Kingdom, and the United States. ${ }^{10}$ According to the Motor Vehicle Manufacturers Association of the United States, these

\footnotetext{
${ }^{10}$ French trade data are from Statistiques du Commerce Exterieur de la France, Institut National de la Statistique et des Etudes Economiques. French production data were obtained by corresfiondence with the Institut National. German trade data are from Aussenhandel nach Waren und Landern Fachserie 7 Reihe 2, and production data are from Produzierendes Gewerbe Fachserie 4 Reine 3.1; both from Statistisches Bundesamt. Japanese trade data are from Japan Exports and Imports: C'ommodity by Country, Japan Tariff Association. Japanese production data were obtained by correspondence with the Economic Planning Agency. Swedish trade data are from Utrikeshandel and production data are from Industri; both are annual publications of Statistics Sweden. U.S. trade data are from U.S. Exports: Schedie B Commodity by Country and U.S General Imports: Schedule A and production date are fro: Annual Census of Manufactures; all are published by the Department of Commeice. Can 'ian trade dat. are from Exports, Merchandise Trade and Imports, Merchandise Trade and production ciata are froni Annuui Survey of Manufactures; all are from Statistics Canada. U.K. trade data are from Annuc: Statement of the Overseas Trade of the United Kingdom and production data are from Monthly Digest of Statistics; both are published by the Central Statistical Office.
} 
seven countries accounted for 80 percent of the non-communist world's automobile production in 1988. To our knowledge this is the only dataset that matches exports and domestic sales to obtain a nearly complete picture of the automobile market in a broad range of countries.

The price data are domestic and export unit values of shipments of passenger cars from the producing countries to themselves, plus five nonproducing countries: Norway, Finland, Austria, Switzerland, and Israel. ${ }^{11}$ The market share data are based on number of units shipped and are obtained from the same sources as the unit value data. For the producing countries, total market sales are determined by adding total production and total imports and subtracting total exports. For the five nonproducing countries, total market sales are assumed to be total imports from the seven producing countries in our sample. Exchange rate data are annual average nominal exchange rates from the IMF International Financial Statistics. Marginal cost data are proxied by total production unit values.

The behavioral equations are estimated for sales from four producing countries-France, Germany, Sweden, and the United States--in all 12 destination markets, for a total of 48 bilateral relationships. ${ }^{12}$ The destination markets were chosen to include both major auto producers and some countries that rely on imports

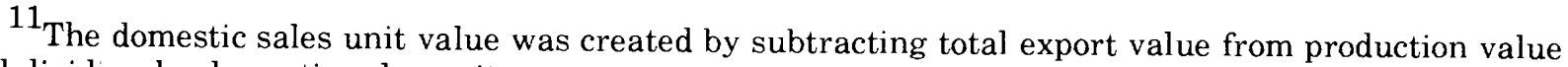
and dividing by domestic sales units.

12 Our original intention was to include the United Kingdom, Canada, and Japan in our sample of exporters. We decided not to estimate pass-through behavior for U.K. and Canadian exports because the unit value data were very noisy due to the low volume of exports to a number of the destination markets. An earlier version of this paper included Japanese exports, but since Japanese auto producers face explicit or implicit quantitative restrictions in many of our destination markets we decided to eliminate them from our sample, also.
} 
exclusively. Since major producing countries tend to dominate their home markets, including only major producing countries as destination markets would leave few source-destination market pairs with intermediate market shares. Exporters would have a large share of the home market and a small share of the other destination markets. The smaller, nonproducing countries provide bilateral relationships with intermediate market share values. These observations will help identify whether market share affects pass-through.

\section{Estimation}

The estimating equation constitutes a long-run equilibrium pricing condition based on the theoretical models of the previous section. Since all of the variables in equation (9) except the market shares appear to be integrated of order one, it is natural to think of the equilibrium as a cointegrating relationship. The empirical results below support this interpretation.

The theoretical models did not examine the dynamic adjustment paths of consumers and firms to income and exchange rate shocks. In the short run, deviations from the equilibrium relationship between export prices, marginal costs, and market shares will be determined by the simultaneous interaction of consumers and firms, and it will be affected by considerations such as the currency denomination of trade contracts. Rather than model these interactions explicitly, we follow Phillips and Loretan (1991) in using an estimating procedvre for long-run equil bria that i robust to short-run simultaneity and dynamic adjustment lags. In estimation we 
various additional restrictions could be imposed across equations. ${ }^{17}$ All tests used a 5 percent significance level.

Most restrictions on the intercept, adjustment speed, and dynamic coefficients ( $\mu, \alpha, \theta 1, \theta 2, \phi 1, \phi 2)$ were strongly rejected, so we kept those coefficients unrestricted for all of the reported results. Restrictions on the coefficients on destination market expenditure, $\gamma$, were also rejected, but since these restrictions had no discernible impact on the pass-through coefficients, the basic results report estimates with the expenditure coefficients restricted to 4 source and 11 destination effects for ease of interpretation. The intercept terms in the pass-through function, $\beta_{0}$, could be restricted to a constant (which incorporates the France-Canada relationship), three source effects (one for each source country except France), and 11 destination effects (one for each destination except Canada). Further restrictions on the pass-through intercepts were rejected. The restrictions imposed on the estimating equation are summarized in equations (12) and (13):

$$
\begin{gathered}
\beta_{i j t}=\beta_{i .}+\beta_{. j}+\beta_{0}+\beta_{1} s_{i j t-1}+\beta_{2} s_{i j t-1}^{2} \\
\gamma_{i j}=\gamma_{i .}+\gamma_{. j}
\end{gathered}
$$

17 The Wald test is based on the variance-covariance matrix of the unrestricted coefficient estimates, see Harvey (1981, pp. 165-67) for a description. The following test results have incorporated a smallsample correction factor, $(T-p / q) / T$, where $T$ is the number of observations, $p$ is the number of unrestricted parameters, and $q$ is the number of equations. See Whittle (1953). 
The residual autocorrelations from the estimates of (11)-(13) are alnost never significant for any source-destination pair. The equilibrium adjustment coefficients, $\alpha$, take an average value of 0.52 for French exports, 0.56 for German exports, 0.39 for Swedish exports, and 0.18 for U.S. exports, and they are usually significantly less than unity. These results support our hypothesis that equation (9) is a valid cointegrating relationship.

The coefficients that determine the pass-through of costs and exchange rates from each source to each destination market are presented in Table 1. There are three coefficients that are common to every relationship: a constant and linear and quadratic terms on market share. The constant, which embodies the French source and Canadian destination effects on pass-through is virtually zero and insignificant. The linear and quadratic terms on the market share are positive and the quadratic term is significant. ${ }^{18}$ These estimates imply that pass-through rises with market share as market share becomes large, consistent with the main result of the theory section of the paper. While the theory section had no clear result for the effect of market share on pass-through when market share is small, the empirical results imply that pass-through is declining in market share for small market shares, reaching a minimum when the exporting country has a 45 percent market share.

The source effects for Germany, Sweden and the United States are positive and significant, indicating that pass-through is significantly higher from these source

\footnotetext{
${ }^{18}$ The linear and quadratic market shares were orthogonalized for estimation so that the constant term captures pass-through at a 50 percent market share for the France-Canada pair. The linear coefficient captures the slope of the relationship, while the quadratic coefficient captures its curvature. A positive quadratic coefficient implies a bowl shape; a negative coefficient implies a hump shape.
} 
allow for short-run departures from equilibrium by including a lagged disequilibrium term and lagged and lead time-differences of the explanatory variables. ${ }^{13}$ By focusing on the long-run pass-through coefficients, we avoid the maintained assumption that producer unit values precisely capture short-run movements in marginal cost. Instead, we require the weaker assumption that producer unit values move one-for-one with marginal cost in the long run. ${ }^{14}$

The estimating equation based on (9) and the Phillips-Loretan procedure is given by:

$$
\begin{aligned}
\ln p_{i j t}^{*}=\mu_{i j}+ & \beta_{i j t} \ln c_{i t}^{*}+\left(1-\beta_{i j t}\right) \ln \left(p_{j t}^{-i} / e_{i j t}\right)+\gamma_{i j} \ln \left(\left(I_{j t} / e_{i j t}\right) / I_{t}^{i}\right) \\
& +\alpha_{i j}\left[\ln p_{i j t-1}^{*}-\mu_{i j}-\beta_{i j t-1} \ln c_{i t-1}^{*}\right. \\
\left.-\left(1-\beta_{i j t-1}\right) \ln \left(p_{j t-1}^{-i} / e_{i j t-1}\right)-\gamma_{i j} \ln \left(\left(I_{j t-1} / e_{i j t-1}\right) / I_{t-1}^{i}\right)\right] & \\
+ & \theta 1_{i j} \Delta \ln \left(p_{j t}^{-i} / e_{i j t}\right)+\phi 1_{i j} \Delta \ln c_{i t}^{*} \\
+ & \theta 2_{i j} \Delta \ln \left(p_{j t+1}^{-i} / e_{i j t+1}\right)+\phi 2_{i j} \Delta \ln c_{i t+1}^{*}
\end{aligned}
$$

Equation (9) is embedded in the estimating equation in the form of a cointegrating

\footnotetext{
${ }^{13}$ Due to limited degrees of freedom, time differences of the market share and total expenditure variables were not included. The market shares move quite slowly over time, while the total expenditures are highly correlated with the competitors' prices because of the common exchange rate component. To minimize any residual simultaneity bias, the market shares were lagged one year, although the results are not significantly affected by using contemporaneous market shares.

${ }^{14}$ As ar additional check on the effect of simultaneity in this measure of marginal cost, the producer unit values were regressed on a time trend and the wholesale price index for each exporting country separately. The fitted values were then used for marginal cost in the standard estimating equation. While the resulting coefficient standard errors are not appropriate for statistical inference, the coefficient values were extrernely close to those of the basic regression for almost all parameters of interest, and they were always within two standard errors of the reported coefficients.
} 
relationship between export price, marginal cost, competitors' price, and market expenditure. Because the marginal cost proxy for each exporter is equal to his total world sales price, world market expenditure cannot have an effect on world sales price by construction. Therefore, the market expenditure variables were expressed as the ratio of expenditure in the destination market to total expenditure in all markets. The coefficient $\alpha$ estimates the speed of adjustment to deviations from equilibrium; if equation (9) is a valid cointegrating relationship, $\alpha$ should be significantly less than unity. The coefficients $\theta 1, \theta 2, \phi 1, \phi 2$ allow for reasonably general short-run dynamics due to adjustment costs, simultaneity, and feedback from dependent to independent variables.

The estimating equation was initially estimated for the 48 source-destination pairs without any cross-equation restrictions. ${ }^{15}$ In many cases, the linear and quadratic market-share effects on pass-through were not not well-estimated and prevented the convergence of the estimation algorithm. In order to obtain convergence, we were forced to constrain these coefficients, $\beta_{1}$ and $\beta_{2}$, to be equal for all source-destination pairs. ${ }^{16}$ We then performed Wald tests to determine whether

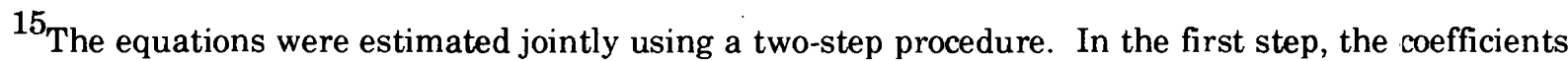
were estimated by minimizing the total sum of squared residuals across all equations. In the second step, the squared residuals for each equation were weighted by the inverse of the estimated equation variance from the first step. Limited trials repeating the second step demonstrated little change in the estimated parameters. This procedure is an approximation to maximum likelihood with a diagonal covariance matrix of residuals. Because of the large number of equations relative to observations, it is not feasible to estimate an unrestricted covariance matrix.

16 We estimated a version of the model with a cubic pass-through function, but the estimated cubic coefficient was small and we could not reject the restriction that the relationship is quadratic. 
countries than from France, although differences between Germany, Sweden, and the United States are not significant. Relatively high pass-through by U.S. and German auto producers is consistent with previous research by Gagnon and Knetter (1990). Abstracting from market share effects, the coefficients for each source must be added to the constant term to determine pass-through from the source country to Canada.

The destination market effects are differences from the Canada destination effect, which is implicit in the constant term in the pass-through formula. Very few of the destination market effects are individually significant, although the main exception is the United States, which has a coefficient of -.88 , indicating that pass-through of automobile prices to the United States is much lower than it is to Canada or any other destination market at similar market shares for a given exporter.

The destination market expenditure coefficients, $\gamma$, are very small. (See Table 2.) Indeed, by adding the source and destination effects together, it is apparent that the effect of market expenditure on export prices from France, Germany, and Sweden is negligible and insignificant for nearly all destinations. Market expenditure does have a small but significant negative effect on U.S. export prices to all destinations. We are slightly puzzled by this last result, but the presence or absence of market expenditure coefficients has very little effect on the estimated pass-through coefficients.

Figures 3-10 display the estimated pass-through relationship for eight representative source-destination pairs. The + symbols indicate two-standard- 
deviation bands above and below the estimated pass-through elasticities. Because the linear and quadratic market share coefficients are constrained to be equal. across all source-destination pairs, the curvature of the pass-through relationship is the same in all plots. The vertical position of the curve is shifted by the estimated source and destination effects. The standard errors also vary with the covariance of the source, destination, and market share coefficients. Among source countries, France and the United States are the two extremes, with French exporters showing almost no pass-through, and U.S. exporters showing more complete pass-through. Among destination countries, the United States and Switzerland are the extremes, with the United States receiving the least pass-through and Switzerland the most.

\section{Conclusion}

This paper derives a theoretical relationship between pass-through and market share for monopolistically competitive exporters. The degree of pass-through depends on the functional form of demand at small market shares, but it rises to a value of one as market share approaches unity for a group of exporters from one country. The data on automobile exports tend to support this relationship between pass-through and market share. Pass-through decreases with market share for low market shares, but it rises at an increasing rate as market share grows large. Pass-through also varies substantially across different exporting and importing countries. Source country differences are driven largely by the lack of pass-through in French exporte? behavior, with German, Swedish, and U.S. behavior quite similar. Destination 
market differences are greatest between the United Kingdom and the United States-with very low pass-through--and Switzerland--with very high pass-through. 


\section{Table 1: Export Price Pass-Through Coefficients}

$\begin{array}{ccc}\text { Intercept } & \begin{array}{c}\text { Market } \\ \text { Share }\end{array}\left(\beta_{1}\right) & \begin{array}{c}\text { Squared } \\ \text { Share }\end{array}\left(\beta_{2}\right) \\ -.14 & .04 & .52^{* *} \\ (.23) & (.09) & (.08)\end{array}$

Source Effects $\left(\beta_{i .}\right)$

$\begin{array}{cccc}\underline{\mathrm{F}} & \underline{\mathrm{G}} & \underline{\mathrm{S}} & \underline{\mathrm{U}} \\ \text { n.a. } & .80^{* *} & .51^{* *} & .82^{* *} \\ & (.16) & (.15) & (.14)\end{array}$

Destination Effects $\left(\beta_{. j}\right)$

$\begin{array}{cccccc}\underline{\mathrm{C}} & \underline{\mathrm{E}} & \underline{\mathrm{F}} & \underline{\mathrm{G}} & \underline{\mathrm{J}} & \underline{\mathrm{S}} \\ \text { n.a. } & -.63^{*} & -.20 & -.12 & .28 & -.14 \\ & (.26) & (.27) & (.27) & (.26) & (.25) \\ \underline{\mathrm{U}} & \underline{\mathrm{N}} & \underline{\mathrm{L}} & \underline{\mathrm{A}} & \underline{\mathrm{Z}} & \underline{\mathrm{I}} \\ -.88^{*} & -.46 & .25 & .25 & .57 & -.12 \\ (.29) & (.26) & (.25) & (.25) & (.25) & (.29)\end{array}$

Note: This table presents estimates of equations (11)-(13) over the years 1972-87. The countries are Canada (C), United Kingdom (E), France (F), West Germany (G), Japan (J), Sweden (S), United States (U), Norway (N), Finland (L), Austria (A), Switzerland (Z), and Israel (I).

* denotes significance at 5 percent level.

** denotes significance at 1 percent level. 
Table 2: Market Expenditure Effects on Export Prices

\begin{tabular}{|c|c|c|c|}
\hline \multicolumn{4}{|c|}{ Source Effects $\left(\gamma_{i}\right)$} \\
\hline$\underline{F}$ & $\underline{G}$ & $\underline{\mathrm{S}}$ & $\underline{\mathrm{U}}$ \\
\hline $\begin{array}{l}.006 \\
(.003)\end{array}$ & $\begin{array}{l}.006 \\
(.003)\end{array}$ & $\begin{array}{l}.005 \\
(.003)\end{array}$ & $\begin{array}{l}-.007 * \\
(.003)\end{array}$ \\
\hline
\end{tabular}

\begin{tabular}{llllll}
\multicolumn{7}{c}{ Destination Effects $\left(\gamma_{j}\right)$} \\
$\underline{\mathrm{C}}$ & $\underline{\mathrm{E}}$ & $\underline{\mathrm{F}}$ & $\underline{\mathrm{G}}$ & $\underline{\mathrm{J}}$ & $\underline{\mathrm{S}}$ \\
n.a. & -.004 & .002 & -.000 & $-.009^{*}$ & -.007 \\
& $(.003)$ & $(.003)$ & $(.003)$ & $(.004)$ & $(.003)$ \\
$\underline{\mathrm{U}}$ & $\underline{\mathrm{N}}$ & $\underline{\mathrm{L}}$ & $\underline{\mathrm{A}}$ & $\underline{\mathrm{Z}}$ & $\underline{\mathrm{I}}$ \\
-.008 & $-.010^{*}$ & -002 & $-.008^{*}$ & $-.009^{*}$ & -.002 \\
$(.004)$ & $(.003)$ & $(.003)$ & $(.003)$ & $(.003)$ & $(.003)$
\end{tabular}

Note: See Table 1. 


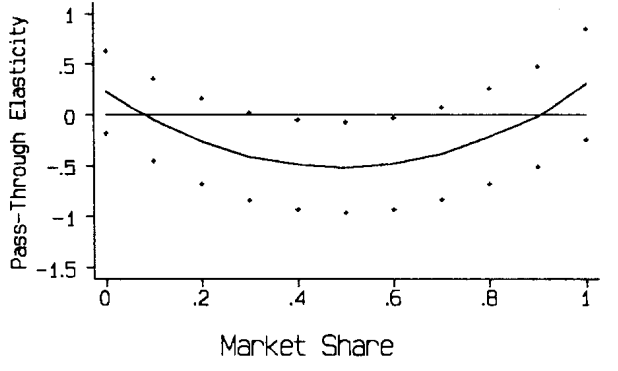

Figure 3 French Exports to Germany

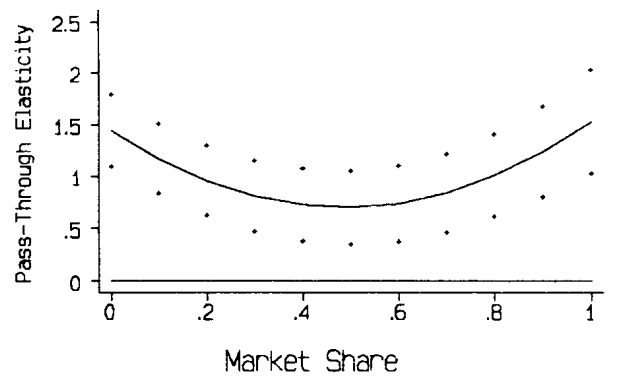

Figure 5 U.S. Exports to Japan

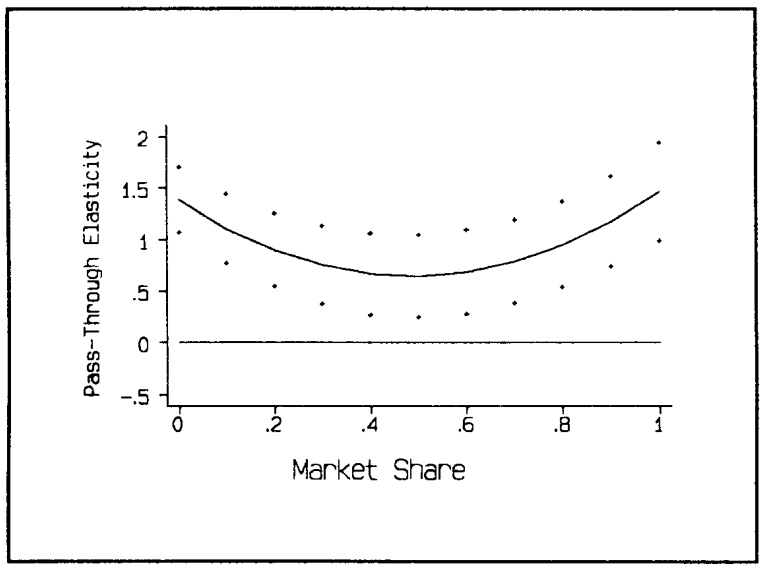

Figure 7 German Exports to Finland

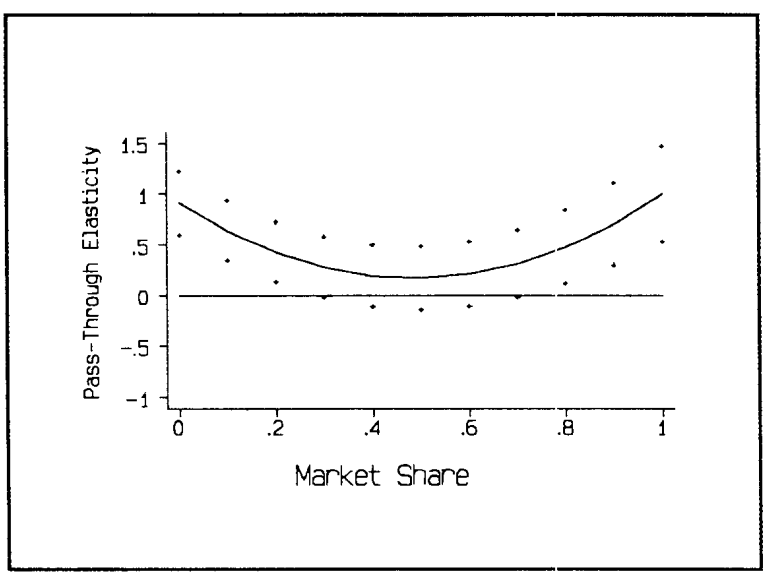

Figure 4 French Exports to Swiss

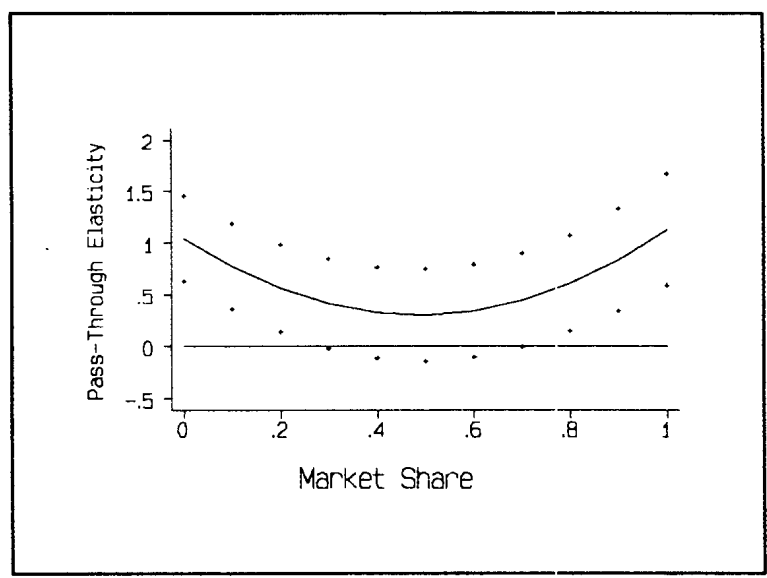

Figure 6 U.S. Exports to Israel

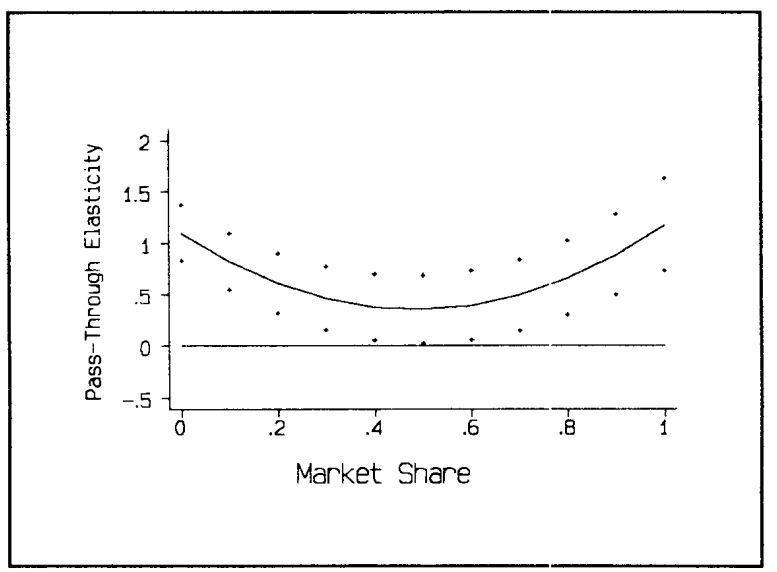

Figure 8 Swedish Exports to Finland 


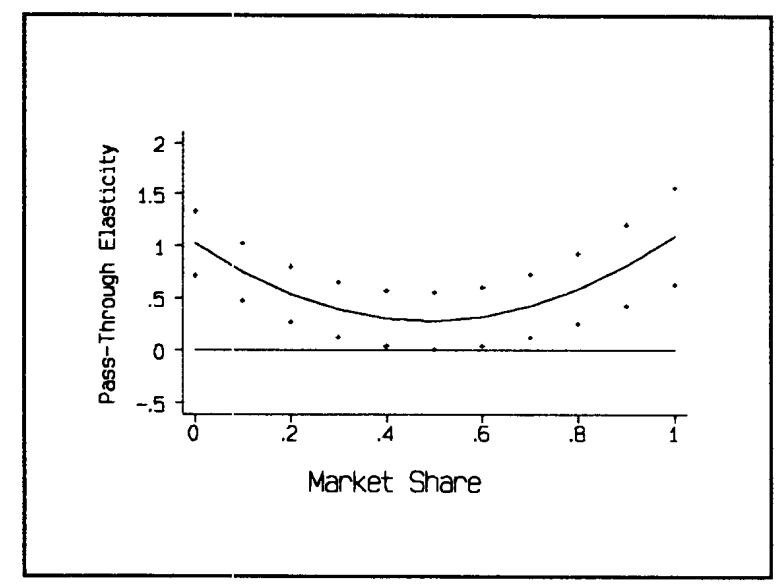

Figure 9 German Domestic Sales

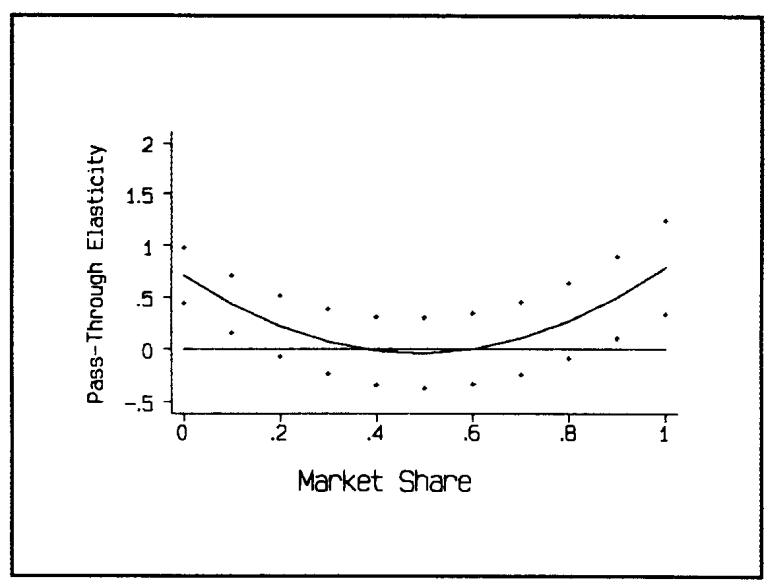

Figure 10 Swedish Domestic Sales 


\section{References}

Dornbusch, Rudiger (1987) "Exchange Rates and Prices," American Economic Review 77, 93-106.

Feenstra, Robert (1989) "Symmetric Pass-Through of Tariffs and Exchange Rates under Imperfect Competition: An Empirical Test," Journal of International Economics 27, 25-45.

Fisher, Eric (1989) "A Model of Exchange Rate Pass-Through," Journal of International Economics 26, 119-37.

Gagnon, Joseph, and Michael Knetter (1990) "Pricing to Market in International Trade: Evidence from Panel Data on Automobiles and Total Merchandise," International Finance Discussion Papers No. 389, Board of Governors of the Federal Reserve System.

Harrison, Ann (1992) "Imperfect Explanations for Imperfect Pass-Through: Market Power and Exchange Rates in the U.S. Steel Industry," unpublished manuscript, The World Bank.

Harvey, A. C. (1981) The Econometric Analysis of Time Series (Philip Allan, Oxford).

Kirman, Alan, and Nathalie Schueller (1992) "Market Structure, Producer Costs and Location: An Alternative View of Pricing in the European Car Market," in M. Dagenais and P. Muet, eds., International Trade Modelling (Chapman and Hall, London).

Knetter, Michael (1989) "Price Discrimination by U.S. and German Exporters," American Economic Review 79, 198-210.

, (1993) "International Comparisons of Pricing-to-Market Behavior," American Economic Review 83, 473-86.

Le Cacheux, Jacques, and Lucrezia Reichlin (1992) "Exchange Rates and Import Prices: Evidence of Pricing to Market in European Car Markets," in M. Dagenais and P. Muet, eds., International Trade Modelling (Chapman and Hall, London).

Mann, Catherine (1986) "Prices, Profit Margins, and Exchange Rates," Federal Reserve Bulletin, June, 366-79. 
Marquez, Jaime (1991) "The Econometrics of Elasticities or the Elasticity of Econometrics: An Empirical Analysis of the Behavior of U.S. Imports," International Finance Discussion Papers No. 396, Board of Governors of the Federal Reserve System.

Marston, Richard (1990) "Pricing to Market in Japanese Manufacturing," Journal of International Economics 29, 217-36.

Mertens, Yves, and Victor Ginsburgh (1985) "Product Differentiation and Price Discrimination in the European Community: The Case of Automobiles," Journal of Industrial Economics 34, 151-66.

Ohno, Kenichi (1989) "Export Pricing Behavior of Manufacturing: A U.S.-Japan Comparison," IMF Staff Papers, 550-79.

Phillips, Peter, and Mico Loretan (1991) "Estimating Long-Run Economic Equilibria," Review of Economic Studies 58, 407-36.

Whittle, Peter (1953) "The Analysis of Multiple Stationary Time Series," Journal of the Royal Statistical Society Series B, 125-39. 
International Finance Discussion Papers

IFDP

NUMBER

446 Market Share and Exchange Rate

Pass-Through in World Automobile Trade

445 Industry Restructuring and Export

Performance: Evidence on the Transition

in Hungary

444 Exchange Rates and Foreign Direct

Investment: A Note

443 Global versus Country-Specific Productivity Shocks and the Current Account

442 The GATT's Contribution to Economic Recovery in Post-War Western Europe

441 A Utility Based Comparison of Some Models of Exchange Rate Volatility

440 Cointegration Tests in the Presence of Structural Breaks

$\underline{1992}$

439 Life Expectancy of International Cartels: An Empirical Analysis

438

437

436 Growth, Political Instability, and the Defense Burden

435 Foreign Exchange Policy, Monetary Policy, and Capital Market Liberalization in Korea

434 The Political Economy of the Won:

U.S.-Korean Bilateral Negotiations on

Exchange Rates
$\underline{\operatorname{AUTHOR}(\mathrm{s})}$

Robert C. Feenstra

Joseph E. Ga.gnon

Michael M. Knetter

Valerie J. Chang

Catherine L. Mann

Guy V.G. Stevens

Reuven Glick

Kenneth Rogoff

Douglas A. Lrwin

Kenneth D. West

Hali J. Edison

Dongchul Cho

Julia Campos

Neil R. Ericsson

David F. Hendry

Jaime Marquez

Geert J. Almekinders

Sylvester C.W. Eijffinger

William R. Melick

Charles P. Thomas

Stephen Brock Blomberg

Deborah J. Lindner

Deborah J. Lindner

Please address requests for copies to International Finance Discussion Papers, Division of International Finance, Stop 24, Board of Governors of the Federal Reserve System, Washington, D.C. 20551. 
IFDP

NUMBER

433

432

431
International Finance Discussion Papers

TITLES

$\underline{1992}$

Import Demand and Supply with Relatively

Few Theoretical or Empirical Puzzles

The Liquidity Premium in Average Interest Rates

The Power of Cointegration Tests

The Adequacy of the Data on U.S. International Financial Transactions:

A Federal Reserve Perspective

Whom can we trust to run the Fed?

Theoretical support for the founders views

Stochastic Behavior of the World Economy under Alternative Policy Regimes

Real Exchange Rates: Measurement and Implications for Predicting U.S. External Imbalances

Central Banks' Use in East Asia of Money Market Instruments in the Conduct of Monetary Policy

Purchasing Power Parity and Uncovered Interest Rate Parity: The United States 1974 - 1990

Fiscal Implications of the Transition from Planned to Market Economy

Does World Investment Demand Determine U.S. Exports?

The Autonomy of Trade Elasticities: Choice and Consequences

German Unification and the European Monetary System: A Quantitative Analysis

Taxation and Inflation: A New Explanation for Current Account Balances
$\underline{\operatorname{AUTHOR}(s)}$

Andrew M. Warner

Wilbur John Coleman II Christian Gilles

Pamela Labadie

Jeroen J.M. Kremers

Neil R. Ericsson

Juan J. Dolado

Lois E. Stekler

Edwin M. Truman

Jon Faust

Joseph E. Gagnon

Ralph W. Tryon

Jaime Marquez

Robert F. Emery

Hali J. Edison William R. Melick

R. Sean Craig

Catherine L. Mann

Andrew M. Warner

Jaime Marquez

Gwyn Adams

Lewis Alexander

Joseph Gagnon

Tamim Bayoumi

Joseph Gagnon 